\title{
VIOLÊNCIA CONTRA A MULHER TRANSGÊNERO: PARA ALÉM DA AGRESSÃO FÍSICA
}

\author{
Renan Ribeiro de Moraes ${ }^{1}$ \\ Larissa Fava Silva ${ }^{2}$ \\ Luiz Carlos Andrade de Aquino ${ }^{3}$ \\ Daniel Lipparelli Fernandez ${ }^{4}$ \\ Maurício Martins Alves ${ }^{5}$
}

Resumo: A situação em que vivem as mulheres transgêneros no Brasil é assustadora. É um grupo com 90\% de seus membros se prostituindo, expectativa de vida não superior a trinta e cinco anos e que mora no país que mais mata a população trans no mundo. Esse artigo tem por objetivo apontar a realidade opressora a que está submetida a transgênero no Brasil em situações que transcendem à violência física, mas que servem como seus alicerces, chamadas aqui de violência psicológica baseada no conceito de violência simbólica do renomado sociólogo francês Pierre Bourdieu. Esta violência psicológica foi aqui subdividida em social, institucional e linguística, observando suas variações conforme o poder aquisitivo da violentada. Utilizando-se de estudos de Maria Berenice Dias e Berenice Bento, pesquisadoras do Direito Civil e Ciências Sociais, foi possível expor dificuldades encontradas por elas sob o viés jurídico-social e, mirando propostas legislativas, especificamente o PL 5.002/2013 e o Estatuto da Diversidade Sexual, conclui-se que para garantir sua plena humanização, faz-se necessário a combinação do dispositivo legal com a representatividade social.

Palavras-chave: Mulher transgênero; Violência simbólica; Brasil.

\footnotetext{
${ }^{1}$ Direito/Universidade do Vale do Paraíba, Brasil. E-mail: renanribeiro@hotmail.com.

2 Direito/Universidade do Vale do Paraíba, Brasil. E-mail: larissa.fava.s@outlook.com.

3 Direito/Universidade do Vale do Paraíba, Brasil. E-mail: aquino@univap.br.

${ }^{4}$ Direito/Universidade do Vale do Paraíba, Brasil. E-mail: fernandez@univap.br.

${ }^{5}$ Direito/Universidade do Vale do Paraíba, Brasil. E-mail: mmalves@univap.br.
} 